\title{
WE NEED TO CLARIFY THE MEANING OF WEIGHTS - VALUE-DIFFERENCE MEASUREMENT AND AHP
}

\author{
Raimo P. Hämäläinen \\ Systems Analysis Laboratory, Helsinki University of Technology \\ P.O. Box 1100, FIN-02015 HUT, Finland \\ tel. $+358-9-4513054$, fax $+358-9-4513096$ \\ raimo@hut.fi \\ http://www.sal.hut.fi/
}

\section{Extended Abstract}

Theoretically AHP is based on relative measurement with a ratio scale which is different from the interval scale of traditional MAVT (Saaty, 1997). This implies that the concepts and meanings of criteria or attribute weights are also different. However, in the literature this fact has not been made clear enough to the practitioners. In the current tradition of reporting about AHP applications the weights are easily only seen as a result of the eigenvector estimation procedure. On the other hand DMs, can give the weights a very important role when they communicate and explain their decisions. So, can we be sure that these interpretations match with the underlying theory? Do the stakeholders or citizens understand the weights in the same way? This is an issue of growing importance, for example, in environmental policy formulation where decision analytic methods are becoming increasingly common and important. Also the fact, that multiattribute weighting software running both AHP and other methods is now available to everybody in the internet (Hämälăinen and Mustajoki, 1998), makes it important to pay attention to the correct understanding of the methods.

The MAVT framework has a clear separation of the DMs preference relation, on one hand, and the methodology through which this relation is modelled, on the other hand. Thus, if the DM accepts the underlying axioms and follows the MAVT elicitation procedures, he can be sure of obtaining results which conform to the axioms he has accepted. In the AHP preferences do not exist in isolation of the process of decision support.

Starting from the foundations of multiattribute value measurement, we have demonstrated (Salo and Hämäläinen, 1997) that the value difference interpretation of ratio comparisons allows the AHP weights to be given the same meaning as in MAVT or, in other words, the AHP can be regarded as a variant of MAVT. In MAVT the pairwise comparisons in ratio estimation should be interpreted in terms of value differences between pairs of underlying alternatives. This interpretation is general and applies to all methods (including the AHP and SMART) which makes use of ratio statements in the elicitation of hierarchical models.

This observation does not, however, lead us to make categorical statements about the "correctness" of the procedures applied, or of the similarity of the results that might be obtained in actual decision analyses (Pöyhönen and Hämäläinen, 1997). Instead, we wish to emphasize the analyst's responsibility of being aware of different approaches to preference elicitation. Particularly in the case of significant public policy decisions the interpretation of weights obtained from alternative approaches may be of concern.

The important question is how the weights are explained and understood. In many papers it is made clear that the weights are different if elicited and estimated with a different method or mode of AHP and if the normalization of the final scores is eliminated or not (Belton and Gear, 1997, Donegan, 1997, Hämäläinen and Salo, 1997, Laininen and Hämalläinen, 1999, Saaty, 1997, Schoner et al., 1997, Stam, 1997, Weber, 1997). There is not just one AHP as different modes of questioning including the network process can 
produce different weights. For example, we think that only few practitioners know that the absolute measurement mode of AHP corresponds to the interval scale model of MAVT. Schoner et al. (1997) point out that the weights obtained by the linking pins or referenced AHP can be transformed into interval scale. So far, we have not seen a case where the possibility for such a transformation would have been explained in connection with a real life problem. When reporting about applications we should start a new tradition of really explaining what the method or mode in question is and how it has been used. Without this the weights cannot be understandable at all.

Recently there has been growing interest in the use of models allowing imprecise preference statements in AHP (see e.g. Hămăläinen and Salo, 1995) and value tree models (see e.g. Salo and Hämäläinen, 1992). There already exists the freely available WINPRE software (Hämäläinen and Helenius, 1998) running these methods. Such approaches are assumed to be attractive as decision makers do not need to specify preferences as point estimates. However, so far we do not have behavioural evidence on the benefits of such relaxations. Moreover, the interpretation of the statements and results can bring additional problems if preference intervals are given a statistical interpretation. This interesting area clearly calls for more research effort.

\section{References and literature}

Belton, V. and Gear, T. (1997) "On the Meaning of Relative Importance", Journal of Multi-Criteria Decision Analysis, 6, 335-338.

Donegan, H.A. (1997) "Some Comments on the Paper "On the Measurement of Preferences in the Analytic Hierarchy Process" by A.A. Salo and R.P. Hämäläinen, Journal of Multi-Criteria Decision Analysis, 6, 321-322.

Dyer, J.S. and Sarin, R.K. (1979) "Measurable Multiattribute Utility Functions", Oper. Res., 27, 810-822.

French, S., Simpson, L., Atherton, E., Belton, V., Dawes, R., Edwards, W., Hämaläinen, R.P., Larichev, O., Lootsma, F., Pearman, A. and Vlek, C., (1998) "Problem Formulation for Multi-Criteria Decision Analysis: Report of a Workshop", Journal of Multi-Criteria Decision Analysis, 7, 242-262.

Hämälăinen, R.P. and Helenius, J., (1998) "WINPRE - Workbench for Interactive Preference Programming", Computer software, Systems Analysis Laboratory, Helsinki University of Technology. (Downloadable for free: http://www.sal.hut.fi/Downloadables/)

Hämäläinen, R.P., Kettunen, E., Marttunen, M. and Ehtamo, E. (1999) "Towards decision and negotiation support in multi-stakeholder development of lake regulation policy", Proc. of the Hawaii International Conference on System Sciences, IEEE Computer Society Press, Hawaii, January 5-8, 1999. (http://www.hut.fi/Units/SAL/Publications/p-index.html)

Hămăläinen, R.P. and Mustajoki, J., (1998) "Web-HIPRE - Java-applet for Value Tree and AHP Analysis", Computer software, Systems Analysis Laboratory, Helsinki University of Technology. (http://www.hipre.hut.fi)

See also: http://www.hut.fi/Units/SAL/Publications/ppt-files/Web-HIPRE/sld001.htm

Hămäläinen, R.P. and Leikola, O. (1996) "Spontaneous Decision Conferencing with Top-Level Politicians", OR Insight, Vol. 9, Issue 1, 24-28.

Hämăläinen, R.P. and Salo, A.A. (1997) "Rejoinder: The Issue is Understanding the Weights", Journal of Multi-Criteria Decision Analysis, 6, 340-343.

Laininen, P. and Hämäläinen, R.P. (1999) "Analyzing AHP-matrices by robust regression", Proceedings of the 5th International Symposium on the Analytic Hierarchy Process (ISAHP'99), August 12-14, 1999, Kobe, Japan. 
Marttunen M. and Hämäläinen, R.P., (1995) "Decision Analysis Interviews in Environmental Impact Assessment", European Journal of Operational Research, Vol. 87, No. 3, 551-563.

Poyhönen, M., Hämäläinen, R.P. and Salo, A. (1997) "An Experiment on the Numerical Modeling of Verbal Ratio Statements", Journal of Multi-Criteria Decision Analysis, 6, 1-10.

Pöyhönen, M. and Hämäläinen, R.P. (1998) "Notes on the Weighting Biases in Value Trees", Journal of Behavioral Decision Making, 11, 139-150.

Pöyhönen, M. and Hämälainen, R.P. (1997), "On the Convergence of Multiattribute Weighting Methods", Helsinki University of Technology, Systems Analysis Laboratory Research Reports, A66, 1-25.

(http://www.hut.fi/Units/SAL/Publications/m-index.html)

Pöyhönen, M., Vrolijk, H. and Hämaläinen, R.P. (1997), "Behavioral and Procedural Consequencies of Structural Variation in Value Trees", Helsinki University of Technology, Systems Analysis Laboratory Research Reports, A69, 1-17. (http://www.hut.fi/Units/SAL/Publications/m-index.html)

Saaty, T.L. (1997) "That Is Not the Analytic Hierarchy Process: What the AHP Is and What It Is Not", Journal of Multi-Criteria Decision Analysis, 6, 324-335.

Saaty, T.L., Vargas, L.G. and Wendell, R.W. (1983) "Assessing Attribute Weights by Ratios", Omega, $11,9-12$.

Salo, A.A. (1993) " Inconsistency Analysis by Approximately Specified Priorities", Math. Comput. Model., 17, 123-133.

Salo, A.A. and Hämäläinen, R.P. (1992) "Preference assessment by imprecise ratio statements, Operations Research, 40, No. 6, 1053-1061.

Salo, A.A. and Hämăläinen, R.P. (1992) "Rank Reversal in the Feedback Technique of the Analytic Hierarchy Process", Helsinki University of Technology, Systems Analysis Laboratory Research Reports A45.

Salo, A.A. and Hümäläinen, R.P. (1992) "PRIME - Preference ratios in multiattribute evaluation", Helsinki University of Technology, Systems Analysis Laboratory Research Reports A43. (Revised 1999). (http://www.hut.fi/Units/SAL/Publications/m-index.html)

Salo, A.A. and Hämåläinen, R.P. (1995) "Preference programming through approximate ratio comparisons", European Journal of Operational Research, Vol. 82, Issue 3, pp. 458-475

Salo, A.A. and Hämäläinen, R.P. (1997) "On the Measurement of Preferences in the Analytic Hierarchy Process", Journal of Multi-Criteria Decision Analysis, 6, 309-319.

Schoner, B., Choo, E.U. and Wedley, W.C. (1997) "Comment on Salo and Hämäläinen's Paper", Journal of Multi-Criteria Decision Analysis, 6, 322-324.

Stam, A. (1997) " Short Note on "On the Measurement of Preferences in the Analytic Hierarchy Process" by A.A. Salo and R.P. Hämäläinen, Journal of Multi-Criteria Decision Analysis, 6, 338-339.

Weber, M. (1997) "Remarks on the Paper "On the Measurement of Preferences in the Analytic Hierarchy Process" by A.A. Salo and R.P. Hämäläinen, Journal of Multi-Criteria Decision Analysis, 6, 320-321. 